ISSN: 0213-2060

DOI: http://dx.doi.org/10.14201/shhme2014324772

\title{
LA SOCIEDAD RURAL EN MEDELLÍN (C 1450-C 1550). ÉLITES, LABRADORES Y POBRES*
}

\author{
The Rural Society in Medellin (c 1450-c 1550). \\ Elites, Peasants and Poor People
}

Julián CLEMENTE RAMOS

Depto. de Historia. Facultad de Filosofía y Letras. Universidad de Extremadura. Campus Universitario. E-10005 CÁCERES. C. e.: clemente@unex.es

Recibido: 2014-04-04

Revisado: 2014-07-17

Aceptado: 2014-10-03

BIBLID [0213-2060(2014)32;47-72]

RESUMEN: La sociedad rural de Medellín entre 1450 y 1550 se caracteriza por una importante estratificación económica. Un grupo enriquecido cuenta con una importante propiedad ganadera y participa en la explotación de las dehesas locales. Los labradores acomodados acumulan bueyes y algunas decenas de cabezas de ganado. El grupo de labradores mantiene una enorme importancia. Por debajo de estos grupos aparece un colectivo de asalariados y pobres.

Palabras clave: Sociedad rural. Campesino. Élites rurales. Pastores. Pobreza.

ABSTRACT: The rural society of Medellin between mid-1 $5^{\text {th }}$ century and mid- $16^{\text {th }}$ century is characterized by a considerable economic stratification. A wealthy group of people are livestock owners and exploits local dehesas. Well-off peasants (labradores) are of great importance in the community and own some livestock and plowing oxen. Wage earners and poor people complete the overal picture beneath the mentioned groups.

Keywords: Rural society. Peasant. Rural elites. Herdsmen. Poverty.

* Este trabajo ha sido realizado en el marco del Proyecto HAR2010-15238, del Ministerio de Economía y Competitividad.

Abreviaturas: AGS-CR = A. G. Simancas, Consejo Real; AChGra = Archivo de la Chancillería de Granada .

(C) Ediciones Universidad de Salamanca

Stud. hist., H. ${ }^{a}$ mediev., 32, 2014, pp. 47-72 
SUMARIO: 0 Introducción. 1 Élites rurales y campesinos enriquecidos. 1.1 Un grupo de ganaderos medios. 1.2 Campesinos enriquecidos. 2 Campesinos medios: los labradores. 3 Asalariados y pobres. 3.1 Domésticos y criados. 3.2 Pastores. 3.3 Pobres y pobreza. 4 Comunalismo agrario y sociedad rural: el ejemplo de Villar de Rena. 5 Conclusiones.

La sociedad rural de los siglos XV y XVI presenta un perfil definido respecto de periodos precedentes. El crecimiento demográfico del siglo xv sitúa los niveles poblacionales en un nivel de cierta entidad, aunque estemos aún lejos del máximo que se marcará en el periodo contemporáneo. No faltan indicios de la necesidad de adaptar la relación con el medio y la explotación de los recursos a la nueva coyuntura, caracterizada por una presión más intensa sobre el espacio.

Las relaciones sociales han sufrido también algunos cambios importantes. Se ha desarrollado una nobleza u oligarquía urbana que entierra definitivamente la caballería popular o villana bajomedieval ${ }^{1}$. Esto supone una cerrazón sociojurídica que impedirá ascensos sociales como el que benefició al grupo indicado. Los miembros más cualificados de este colectivo se sustentan económicamente en la propiedad de espacios de pastos (dehesas). El ascenso de sectores minoritarios populares se limitará en lo sucesivo al ámbito económico, sin que tenga su correlato en el social ${ }^{2}$.

La evolución de los grupos campesinos se ha visto facilitada por una renta señorial estancada y/o moderada. No se ha valorado en términos globales. Sería de gran interés abordarla conjuntamente con la fiscalidad real. Las punciones señoriales, reales y eclesiásticas realizadas sobre el campesinado no han impedido fenómenos de acumulación y enriquecimiento. Esta circunstancia se ha visto favorecida por la escasa o limitada progresividad fiscal. No faltan indicios, tampoco, de una cierta mejora de la condición campesina en líneas generales. En este sentido, la generalización del trigo como prácticamente único cereal panificable es un indicador significativo ${ }^{3}$.

1 Monsalvo Antón, José María. «Transformaciones sociales y relaciones de poder en los concejos de frontera, siglos XI-XIII. Aldeanos, vecinos y caballeros ante las instituciones municipales». En Relaciones de poder, de producción y de parentesco en la Edad Media y Moderna. Aproximación a su estudio. Madrid, 1990, p. 165; Diago Hernando, Máximo. "Caballeros e hidalgos en la Extremadura castellana medieval (siglos XII-XV)». En la España Medieval, 1992, vol. 12, pp. $42-43$ y 52; Gerbet, M. ${ }^{e}$ Claude. «Essai sur l'apparition d'une moyenne noblesse dans l'Estrémadure de la fin de Moyen Âge». En Hernán Cortés y su tiempo. Mérida, 1987, vol. 1, p. 301.

2 Podrían darse alianzas entre la sangre y el dinero que sustenten un ascenso social por vía matrimonial siempre de carácter individual. Estos casos, de producirse, serían minoritarios y compatibles con la cerrazón social indicada: Diago Hernando, Máximo. "Grandes y pequeños ganaderos trashumantes en las sierras sorianas en el tránsito de la Edad Media a la Moderna». Revista de Historia Económica, 1994, vol. XII, n. 2, pp. 348-349; García Garcimartín, Hugo Joaquín. El valle del Alberche en la Baja Edad Media (siglos XII-XV). Âvila, 2004, pp. 222-223.

3 Clemente Ramos, Julián. «Niveles de vida y pautas de consumo en el campesinado (Corona de Castilla, 1200-c. 1550)». En Comer, beber, vivir: consumo y niveles de vida en la Edad Media Hispánica. XXI Semana de Estudios Medievales. Logroño, 2011, pp. 221-225. 
La sociedad rural a finales de la época medieval y comienzos de la moderna presenta una creciente diversificación y la aparición de unos grupos pecheros de un alto nivel económico ${ }^{4}$. Un colectivo reducido llega a alcanzar unos niveles patrimoniales en absoluto desdeñables. La pobreza se sitúa como una preocupación creciente. Es muy probable que se haya intensificado. En todo caso, tendrá una presencia constante en la política concejil a la vez que se difunden los hospitales y las mandas testamentarias dirigidas a este sector social ${ }^{5}$. Los sectores desfavorecidos posiblemente han adquirido un peso creciente y significativo. Siempre es difícil valorar el peso demográfico de los campesinos medios o labradores, auténtica columna económica y social. La sociedad rural de Medellín se ajusta a estas pautas indicadas. Intentaremos precisar los diversos colectivos que la componen, su perfil económico y, en la medida de lo posible, su peso demográfico y significado social.

\section{1 ÉLITES RURALES Y CAMPESINOS ENRIQUECIDOS}

El origen de estas élites rurales es muy difícil de precisar. Sabemos cuándo se han convertido en una realidad consolidada, pero precisar su desarrollo presenta enormes dificultades. Este problema lo vamos a soslayar en un estudio como el presente de interés fundamentalmente sincrónico. En el caso de Medellín, las realidades específicamente campesinas no se perfilan con cierta claridad hasta la segunda mitad del siglo XV y sobre todo en el último cuarto de este siglo. Es evidente que, hasta mediados del siglo XIV, los sectores enriquecidos han podido ascender no solo económica sino también socialmente configurando un grupo privilegiado que se define por el acceso a la propiedad adehesada y su consolidación como minoría privilegiada que terminará disfrutando de un estatus nobiliario. El desarrollo de este proceso ha estado posibilitado por una realidad social abierta donde el ascenso económico no ha encontrado problemas para proyectarse en el

4 Borrero Fernández, Mercedes. «La sociedad rural: los agricultores». Medievalismo, 2004, vol. 13-14, pp. 216-217; García Garcimartín, El valle del Alberche en la Baja Edad Media, p. 208; Asenjo GonzÁlez, María. «Labradores ricos: nacimiento de una oligarquía rural en la Segovia del s. Xv». En la España Medieval, 1984, vol. IV, pp. 63-85; Díez SAnz, Enrique. La tierra de Soria. Un universo campesino en la Castilla oriental del siglo XVI. Madrid, 1995, pp. 254-255; Carrasco TeZanos, Ángel. La sociedad campesina en la sierra de Guadarrama a finales de la Edad Media. Madrid, 2006, p. 144; Gómez-MENor, José. "Una casa de labradores acomodados de la villa de Yepes en 1505. Hacienda, ajuar y precios". Toletum, 1985, vol. XVII, 2. a época, pp. 193-194. Una visión general en Furió, Antoni. "Las elites rurales en la Europa medieval y moderna. Una aproximación de conjunto». En El lugar del campesino. En torno a la obra de Reyna Pastor. Valencia, 2007, pp. 391-421, y Jessenne, Jean-Pierre y Menant, François. «Les élites rurales, objet d'histoire». En Les élites rurales dans l'Europe médiévale et moderne. Flaran, 2005, pp. 10-52.

5 Se manifiesta de muy diversas maneras: Casado Alonso, Hilario. Señores, mercaderes y campesinos. La comarca de Burgos a fines de la Edad Media. Madrid, 1987, pp. 533-535; Oliva Herrer, Rafael Hipólito. La Tierra de Campos a fines de la Edad Media. Economía, sociedad y acción politica campesina. Valladolid, 2002, p. 156; Rodríguez González, M. ${ }^{a}$ del Carmen. Economía y poder en el Bierzo del siglo XV. San Andrés de Espinareda. Santiago de Compostela, 1992, p. 119; MArTín CEA, Juan Carlos. El mundo rural castellano a fines de la Edad Media. El ejemplo de Paredes de Nava en el siglo XV. Valladolid, 1991, pp. 425-426. 
ámbito social ${ }^{6}$. Más allá de mediados del siglo xIV, con la consolidación de una sociedad crecientemente cerrada, será imposible desarrollar procesos similares. La acumulación económica no se proyectará hacia otras esferas. Esto significa que desde el segundo cuarto del siglo xIV, los procesos de enriquecimiento generarán élites pecheras/rurales, pero no nuevos colectivos ennoblecidos.

Estos sectores enriquecidos hacen uso del trabajo asalariado en sus diversas modalidades. Este colectivo se ajusta a un doble perfil, en función de que su acumulación patrimonial se ajuste al modelo económico campesino o que desarrollen una especialización ganadera, más frecuente en zonas de montaña que cuentan con una economía más marcadamente pecuaria. En este último caso, sin duda, la disponibilidad de zonas de pastos en la tierra de Medellín ha debido ser un incentivo importante. Es probable que se dieran situaciones intermedias que una escasa información no permite documentar.

No podemos precisar cronológicamente, el desarrollo de estas élites y sectores enriquecidos. Es probable que hacia mediados del siglo xv, dentro del contexto de crecimiento y cambios que conoce la corona de Castilla, este proceso estuviera muy avanzado. En todo caso, se presenta ya de forma madura a finales de este siglo.

\subsection{Un grupo de ganaderos medios}

Este colectivo dispone de explotaciones que tienen una escasa o nula dedicación agraria. El desarrollo de actividades especializadas está claramente relacionado con una estrecha vinculación con el mercado. Este grupo va a acceder al arriendo de dehesas en concurrencia con serranos y propietarios comarcanos que presentan un perfil social muy similar, caracterizado por su origen rural y su condición pechera ${ }^{7}$.

Estas élites enriquecidas con una clara dedicación ganadera se presentan con nitidez en la primera mitad del siglo Xvi. Posiblemente, nada resulta más decisivo que los datos disponibles sobre los arrendamientos de dehesas, que permiten precisar en términos cualitativos el perfil económico de este colectivo ${ }^{8}$.

6 Clemente Ramos, Julián. La tierra de Medellin (1234-c. 1450). Dehesas, ganadería y oligarquía. Badajoz, 2007, pp. 49-68 y 87-121.

Los datos relativos a la propiedad ganadera de grupos equivalentes se centran en contextos de trashumancia: Diago Hernando, Máximo. «El desarrollo de la trashumancia y los orígenes medievales de la cuadrilla mesteńa soriana». Hispania. Revista Española de Historia, 2004, vol. 64, n. ${ }^{\circ}$ 218, pp. 10591064; ÍDEM, «Grandes y pequeños ganaderos trashumantes en las sierras sorianas en el tránsito de la Edad Media a la Moderna». Revista de Historia Económica, 1994, vol. XII, n. 2, pp. 350-351; Berges SÁNCHEZ, Juan Manuel. Actividad y estructuras pecuarias en la comunidad de Albarracín (1284-1516). Tramacastilla, 2009, pp. 443-447; Villanueva MorTe, Concepción. "La trashumancia y los herbajes de ganado a través de la aduana de Barracas a mediados del siglo Xv». En La trashumancia en la España mediterránea. Historia, antropología, medio natural, desarrollo rural. Zaragoza, 2004, pp. 215-217.

8 El acceso a la explotación de las dehesas por personas de origen pechero también parece detectarse en Cáceres: García Oliva, M. a Dolores. Organización económica y social del concejo de Cáceres y su tierra en la Baja Edad Media. Cáceres, 1990, p. 151. 
CUAdro 1.- Propietarios ganaderos: arrendamiento de dehesas.

\begin{tabular}{|c|c|c|c|}
\hline Arrendatario (vecindad) & Año & Dehesa & Varia \\
\hline Juan Rubio & 1498 & $\begin{array}{l}\text { Valverde, comunales Don } \\
\text { Benito }\end{array}$ & \\
\hline Juan Flores (Guareña) & $1501-1514$ & Guijo & \\
\hline $\begin{array}{l}\text { Juan Nieto (Miajadas), Juan Sánchez de la } \\
\text { Nieta y aparceros }\end{array}$ & 1509 & Ventoso & \\
\hline Bartolomé Sánchez de la Higuera (Miajadas) & 1535 & $\begin{array}{l}\text { Cuadradillo (en aparcería } \\
\text { con otros) }\end{array}$ & \\
\hline Diego Nieto (Miajadas) & 1535 & Cuadrado & \\
\hline Luis Martínez & $(\ldots)-1536$ & Caballería & \\
\hline Pedro Fernández (Miajadas) & $1538-1539$ & ¡en dehesa? & se le mata 1 ańoja \\
\hline algunos vecinos (Don Benito) & 1539 & Peñalobar & \\
\hline algunos vecinos (Miajadas) & 1540 & Cuadrado -parte- & Pasto y labor \\
\hline $\begin{array}{l}\text { Gonzalo Martín del Corral y otros vecinos de } \\
\text { Miajadas y Almoharín }\end{array}$ & 1540 & Cuadrado -3/8- & \\
\hline Bartolomé Hernández (Don Benito) & $\begin{array}{c}1540 \\
1540-15411\end{array}$ & Cuadrado -3/8- & \\
\hline Bernardo M. (¿̨vecino?) & $1540-1541$ & Torrevirote & \\
\hline Diego García (¿vecino?) & $1540-1541$ & Guadalperal & \\
\hline Bachiller Zapardiel, v. ${ }^{\circ}$ Miajadas & $1540-1541$ & Fresneda & \\
\hline Alonso García Calderón (Medellín) & $1541-1542$ & Dehesilla de Camacho & \\
\hline Bachiller Zapardiel, v. ${ }^{\circ}$ Miajadas & 1542 & Dehesa sin precisar & \\
\hline 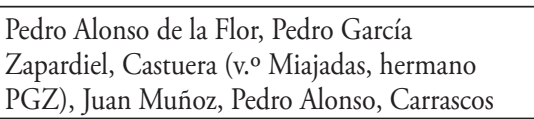 & $1542-1543$ & Arroyo de las Puercas & ¿arriendo o pena? \\
\hline Juan González de Pedro Sánchez & $1542-1543$ & Canchal & ¿arriendo o pena? \\
\hline $\begin{array}{l}\text { Juan Sánchez de Pedro Sánchez, su hermano } \\
\text { Pascual Sánchez: y Martín Alonso de Antequera }\end{array}$ & & Mezquita & ¿arriendo o pena? \\
\hline
\end{tabular}

Juan Rubio, mayoral de las vacas del monasterio de Guadalupe, es sin duda el caso mejor documentado. Su importante capital ganadero le obliga a realizar unos gastos importantes en hierba que hemos calculado en noventa mil maravedís anuales. Estamos mal informados sobre los pastos contratados en 1497-1498. Su ganado pastó en la dehesa de Valverde de Ortega. Igualmente, sus bueyes accedieron a los comunales de Don Benito. Será una opción que también aprovecharán los serranos cuando se generalice el acogimiento de ganado en las dehesas y espacios comunales aldeanos? ${ }^{9}$. El caso de Juan

9 Sobre el tema, Clemente Ramos, Julián. «Élites rurales rurales en Extremadura a finales de la Edad Media. El mayoral Juan Rubio († 1499)». Studia Historica. Historia Medieval, 2012, vol. 29, pp. 229-246, en particular p. 239. 
Rubio nos ilustra sobre la necesidad de acceder de forma venal a los pastos vecinales cuando se acumulaba una importante cabańa. Su excepcionalidad se debe más a su nivel patrimonial que al perfil económico de su explotación.

Algunos indicios cualitativos indican el desarrollo de unas élites rurales que ocupan un nivel económico claramente destacado. En algunas de las aldeas más importantes de la tierra se alude a ellas. En 1502, dentro del pleito que enfrenta al conde de Medellín y a Juan Núñez de Prado, se alude a este sector. Juan Núñez de Prado repartió bueyes y novillos entre "los oficiales e personas que más valen en el logar de Garueña» y entre «los oficiales del concejo e a los omes más honrados» de Miajadas. Diego Nieto y sus parientes, vecinos de esta última aldea, son "los que más valen en el dicho logar de Meajadas» ${ }^{10}$. Posiblemente no es casual que miembros con este apellido aparezcan entre los arrendatarios de dehesas. En 1509, Juan Nieto y Juan Sánchez de la Nieta están entre los aparceros que tienen arrendada la dehesa de Ventoso. En 1535, Diego Nieto tuvo arrendada la dehesa de Cuadrado ${ }^{11}$. En 1532, el procurador condal acusó a los concejos de la villa y la tierra de que los repartimientos que se hacían para pleitear estaban controlados por «los más ricos de los dichos pueblos» ${ }^{12}$. La idea de una élite muy claramente definida de personas cuya acumulación patrimonial les sitúa claramente por encima de los demás es algo perceptible. Este colectivo parece tener conexiones con este sector que hemos definido con intereses claramente ganaderos.

Nuestra información sobre la estructura de las explotaciones de este colectivo es parcial. Los arrendadores de dehesas cuentan sobre todo con ganado vacuno, pese al dominio de otras especies en la ganadería local ${ }^{13}$. Es muy interesante la información contenida en el pleito que enfrenta tardíamente a Valdetorres y Guareña. Se indica que en esta aldea, una de las mayores de Medellín, y en Manchita (La Mancha) «no ay persona ni ha abido desde que los testigos se acuerdan que aya tenido ni tenga sesenta reses bacunas ni treynta yeguas». Esta afirmación es ratificada por testigos que remontan su memoria a 1520 o $1530^{14}$. Aunque sabemos que no era un nivel rígido, sí marca un límite apreciable que nos permite situar un nivel significativo en la acumulación patrimonial de este colectivo $^{15}$. En ese sentido son indicativas también, pese a su ambigüedad, las conclusiones del alcalde mayor sobre la fiscalidad de Miajadas. Determina que en los repartimientos que se realizan a comienzos de la segunda década del siglo xvi a los que tienen ochenta

10 AGS-CR, leg. 686, n. ${ }^{\circ} 10$, fol. 3v.

11 AGS-CR, leg. 73, exp. 8, fol. 25r; y leg. 230, exp. 2-1, fol. 107v.

12 AGS-CR, leg. 230, n. ${ }^{\circ}$ 1, fol. 100r.

13 Sobre la ganadería local, Clemente Ramos, Julián. «La ganadería en Medellín (1450-1550). Propietarios y cabañas». Anuario de Estudios Medievales, 2014, vol. 44, n. 2 (en prensa). El dominio del ganado vacuno explica que la estimación ganadera del espacio adehesado se denomine vaqueamiento, cf. Clemente Ramos, Julián. «El vaqueamiento de las dehesas de Medellín (1460)». Norba. Revista de Historia, 2005, vol. 18, pp. 137-146.

${ }_{14}$ AChGra, leg. actual 31, n. ${ }^{\circ} 1$, fols. 316r, 319v y $323 \mathrm{v}$.

15 Unos niveles patrimoniales equiparables y con un perfil preferentemente ganadero en CARRASCO Tezanos, La sociedad campesina en la sierra de Guadarrama, pp. 144-147; Puñal Fernández, Tomás. «La ganadería lanar en Madrid y su tierra durante la Edad Media». Espacio, Tiempo y Forma. III. Historia Medieval, 1998, vol. 11, pp. 368-370. 
vacas se les reparte como si tuvieran cuarenta y a los de cuarenta como veinte ${ }^{16}$. Si bien el término vaca tiene en este contexto un claro significado fiscal, alude también, probablemente, a la existencia de cabańas vacunas de varias decenas de unidades. Vemos aquí, sin duda, a los propietarios que acceden y necesitan los pastos de las dehesas.

Disponemos de datos dispersos sobre los patrimonios de este colectivo. Destaca su escasa o nula dedicación agraria ${ }^{17}$ y su estricta relación con el negocio ganadero. Si bien este colectivo aparece en la villa y las aldeas, nuestra información está muy vinculada a oficiales de Medellín que han aprovechado las múltiples ventajas derivadas de su situación y de su vinculación en muchos casos con el conde, que cada vez tutela en mayor medida el concejo local.

Cuadro 2.- Propietarios ganaderos: nivel patrimonial.

\begin{tabular}{|c|c|c|c|c|}
\hline Propietario* & Año & \begin{tabular}{|c|}
$\begin{array}{c}\text { Propiedades } \\
\text { agrarias/bueyes }\end{array}$ \\
\end{tabular} & Ganado & Otros \\
\hline Juan Rubio & 1499 & 8 bueyes & $\begin{array}{l}334 \text { vacas, } 83 \text { añojos, } 354 \text { ovejas, } 48 \text { carneros, } \\
280 \text { corderos, } 37 \text { cabezas caprinas, } 1 \text { caballo, } \\
2 \text { yeguas y } 3 \text { potros } \\
\end{array}$ & \\
\hline \multirow[t]{2}{*}{ Francisco López* } & 1543 & & 100 vacas, 600 ovejas, 2 caballos & 1 negra \\
\hline & 1545 & & $\begin{array}{l}92 \text { vacas, } 2 \text { toros, } 44 \text { becerros } \\
<80 \text { puercos } \\
1 \text { caballo } \\
\end{array}$ & $\begin{array}{c}1 \text { esclava } \\
\text { negra }\end{array}$ \\
\hline $\begin{array}{l}\text { Catalina Díaz, mujer } \\
\text { de Francisco López }\end{array}$ & ¿1543? & $\begin{array}{l}6 \text { bueyes } \\
1 \text { viña }\end{array}$ & 80 vacas & $\begin{array}{l}100 \text { fan. } \\
\text { trigo }\end{array}$ \\
\hline Gonzalo Ruiz* & & $3-4$ bueyes & $\begin{array}{l}\text { ¿56-60 vacas?, } 1 \text { asno, } 4-5 \text { puercas, } 1 \text { puerca } \\
\text { parida, } 5 \text { cochinos }\end{array}$ & \\
\hline Antonio Núñez* & & & $\begin{array}{l}200 \text { vacas } \\
\text { (parte: ejecución) }\end{array}$ & \\
\hline Francisco García & 1547 & & $\begin{array}{l}22 \text { vacas, } 1 \text { toro, } 1 \text { caballo, } 1 \text { lechón } \\
\text { (parte: ejecución) }\end{array}$ & \\
\hline
\end{tabular}

Estos patrimonios se caracterizan por el predominio del ganado bovino. Los buenos pastos de las dehesas de Medellín facilitan el desarrollo de esta cabaña, frente al dominio del ganado ovino en general ${ }^{18}$. En algunos casos podría darse una actividad

16 AGS-CR, leg. 230, exp. 6, fol. 174r.

17 Disponemos de ejemplos en los que se dan conjuntamente la propiedad ganadera, con un perfil parecido, y la agraria: Rodríguez Molina, José. «Inicios de la expansión del olivar en Jaén. Andújar (14751575)». En Estudios. Homenaje al profesor Alfonso Sancho Sáez. Granada, 1989, p. 283; Franco Silva, Alfonso. El concejo de Alcalá de Guadaira a finales de la Edad Media. Sevilla, 1974, pp. 101-102.

18 En el primer tercio del siglo xvi se detecta igualmente en Zafra la existencia de un colectivo pechero con importantes cabañas que llegan a alcanzar las quinientas cabezas ovinas (Bernal Estévez, Ángel. «La vida cotidiana en Zafra a principios del siglo xvi. Las ordenanzas municipales de 1528». Cuadernos de Çafra, 2005, vol. III, pp. 231 y 337). 
agraria, aunque como veremos a continuación no puede deducirse por la mera posesión de bueyes.

Conocemos bien el caso de Juan Rubio ${ }^{19}$. Posiblemente, no estamos ante un caso típico. Aunque dispone de un número de bueyes respetable (ocho), la actividad agraria queda absolutamente en la penumbra y solo se documenta la propiedad de dos vińas. Es posible que no desarrollase cultivo cerealista alguno y que estos animales se utilizasen para alquiler, extremo sobre el que igualmente las fuentes permanecen mudas. Juan Rubio es, sobre todo, un ganadero. En primer lugar, por su actividad como asalariado cualificado (mayoral de las vacas). Y, sobre todo, por una propiedad principal y casi exclusivamente pecuaria $(87,51 \%$ del total). Esta propiedad presenta, en oposición a los simples campesinos acomodados, un perfil definido en términos cualitativos (ausencia del ganado porcino) y cuantitativos. El ganado bovino, excluidos los bueyes, alcanza el $86,64 \%$ del valor total. La estructura de esta cabaña se ajusta al perfil dominante en las dehesas. Juan Rubio comparte con los serranos segovianos, que acuden desde hacía décadas a las dehesas de la jurisdicción, su condición de importante propietario ganadero de origen pechero. Los ingresos que obtenía de la venta de animales y cuero (su actividad como prestamista seguramente tiene más importancia social que económica) le permitieron obtener, pese a los elevados gastos en hierba, superávits regulares que posibilitaron una relevante acumulación patrimonial.

La explotación de Juan Rubio se caracteriza por su especialización y estricta vinculación con el mercado. El autoconsumo, elemento central de cualquier unidad campesina, no cumple ningún papel. No conocemos las condiciones concretas en que este personaje fue acumulando su patrimonio. Su vinculación y conocimiento del negocio ganadero, por su relación con el monasterio de Guadalupe, ha debido ser un elemento decisivo. En todo caso, no ha roto su vínculo con esta institución pese a su claro ascenso económico.

A finales de la Edad Media se documenta en Medellín un grupo de propietarios medios ganaderos de origen pechero que accede al arrendamiento de las dehesas en concurrencia con ganaderos serranos y comarcanos de similar perfil social. En la primera mitad del siglo XvI se presenta como un colectivo plenamente constituido. Sus explotaciones se caracterizan por una estricta vinculación con el mercado tanto para el acceso a los recursos (arriendo de dehesas) como para la venta de sus excedentes.

\subsection{Campesinos enriquecidos}

Junto al grupo anterior, definido por una importante dedicación ganadera y el acceso a la explotación de las dehesas, aparece otro colectivo que desarrolla su acumulación patrimonial dentro de los patrones económicos campesinos ${ }^{20}$. El campesino, definido

19 Clemente Ramos, «Élites rurales en Extremadura», pp. 229-246.

20 Del mismo modo, Viciano, Pau. Els peus que calciguen la terra. Els llauradors del Pais Valencià a la fi de l'Edat Mitjana. Valencia, 2012, p. 91, señala cómo los campesinos acomodados valencianos seguían denominándose «llauradors» $\mathrm{y}$ no presentaban «diferències qualitatives en la forma que aquest llauradors rics tenien d'explotar las seues terres -fonamentalment, treball familiar i policultiu de base cerealista, amb l'ajuda d'algun criat agrícola- respecte a la pagesia mitjana». 
por la posesión y/o explotación de tierras de cereal y animales de labranza, se caracteriza por una economía no especializada que presenta importantes elementos autárquicos. Este grupo enriquecido tiene una dedicación preferentemente agraria y solo subsidiariamente pecuaria $^{21}$. Se diferencian de los simples labradores solo por su superior nivel económico.

Este grupo de campesinos enriquecidos o acomodados puede que haya adquirido cierto desarrollo en la segunda mitad del siglo Xv. Ya en la primera mitad se documentan pecheros que desarrollan una actividad de recaudación fiscal ${ }^{22}$. Martín Sancho, aldea que despuebla definitivamente Rodrigo Portocarrero en 1449, poco después de acceder a la jurisdicción de la tierra de Medellín, nos ofrece un caso especial que quizás haya que vincular con este colectivo. Esta aldea, que poco antes de su despoblación contaba con quince-veinte vecinos y presentaba una importante dedicación ganadera (algunos pobladores tenían una vecindad de conveniencia para aprovecharse de unos pastos relativamente abundantes por el declive poblacional), contaba con dos personas de una posición económica y un estatus claramente destacados. Se dice que uno de estos vecinos «hera un labrador de los más honrados e ricos del logar». El binomio riquez/honradez indica no solo una posición económica sino también social. Es indicativo que se utilice el término labrador, de claro y preciso significado. En una aldea claramente desestructurada y con vecinos de conveniencia, esta posición económica se ha proyectado hacia el poder aldeano, monopolizando la alcaldía las dos personas señaladas ${ }^{23}$. Nivel económico, relevancia social y poder local se integran en este futuro despoblado.

La información sobre este colectivo enriquecido es mucho mayor que la disponible para los simples labradores, penalizados por una actividad económica más introvertida, y podemos fijar con mucha más precisión su perfil económico y social. Sus explotaciones se definen por tres elementos fundamentales: posesión de bueyes en un nivel que puede superar la típica yunta, cabañas ganaderas de unas decenas de cabezas que suministran excedentes comercializables y demanda de trabajo asalariado, que en ocasiones pueden cubrir los miembros más jóvenes de la unidad familiar ${ }^{24}$. Se trata de vecinos que podemos definir como labradores (es decir, campesinos) enriquecidos. La actividad agraria es prioritaria aunque no exclusiva y el uso de fuerza de trabajo ajena a la unidad familiar es limitado y puntual. La vinculación con el mercado es importante, pero las explotaciones tienen como principio directriz el autoconsumo. Es posible que algunos miembros de este grupo alcanzasen niveles

21 Una realidad equiparable presenta para la Rioja Brumont, Francis. Campos y campesinos de Castilla la Vieja en tiempos de Felipe II. Madrid, 1984, p. 218. En la zona castellano-manchega propiedad agraria y pecuaria no suelen darse conjuntamente entre los campesinos acomodados, aunque ante la inexistencia de ganaderos especializados fuera de las zonas serranas controlan la cabańa existente: López-SALAZAr PÉrez, Jerónimo. Estructura agraria y sociedad rural en La Mancha (siglos XVI-XVII). Ciudad Real, 1986, pp. 479-481 y $487-488$.

22 «Por quanto los dichos Fernand Garçía e Juan Sánchez e Alvar Sánchez, ansý como arrendadores del diezmo de las yervas del ańo pasado avían resçibido de diezmo de la yerva del Arroyo de las Puercas» (A. Mon. Guadalupe, leg. 123, n. $\left.{ }^{\circ} 10\right)$.

23 Clemente Ramos, Julián. «Martín Sancho (siglos XIV-Xvi). Un despoblado bajomedieval en la tierra de Medellín». Hispania. Revista Española de Historia, 2006, vol. XLVI, n. ${ }^{\circ}$ 223, p. 419; AChGra, leg. 577, n. ${ }^{\circ} 24$, fols. 50v-51r.

24 Esta acumulación de tierras y ganado también se produce en Andújar a principios del siglo XVI: Rodríguez MolinA, «Inicios de la expansión del olivar en Jaén», pp. 283-284. 
patrimoniales equivalentes al que suponemos para el anterior, pero nuestra información sobre el particular es imprecisa.

Los datos disponibles sobre la propiedad de bueyes para 1488 constituyen el mejor indicador de la diversificación económica campesina. Esta información proviene de las prendas realizadas por Juan Núñez de Prado dentro de su enfrentamiento con el conde de Medellín ${ }^{25}$. La mayor parte de los propietarios son de Guareña, de modo que ha quedado registrada gran parte de la cabaña boyal de esta localidad. Debemos considerar que estamos ante una de las tres grandes aldeas de la jurisdicción, que sin duda debieron presentar una sociedad más diversificada. Se aprecia una importante concentración de la propiedad. En todo caso, debemos señalar que el grupo sin bueyes estaría claramente subrepresentado por su escaso peso en la propiedad pecuaria. Del mismo modo, los mayores propietarios estarían sobrerrepresentados. En general, y aún considerando estos elementos, en Guareña el grupo que cuenta con cuatro (número mínimo para disponer de más de una yunta) o más bueyes tendría un peso relativamente importante en el colectivo vecinal (cincuenta y seis de ciento treinta y cinco). Incluso reduciendo a la mitad su peso demográfico, proporción seguramente exagerada, llegaría a representar en torno a una quinta parte de la población local, índice sin duda significativo. A partir de seis bueyes (tres yuntas), el número de propietarios se reduce significativamente, representando solo algo menos de una tercera parte de este colectivo enriquecido.

Cuadro 3.- Guareña, 1488: propietarios de bueyes (4->10).

\begin{tabular}{|l|c|c|c|c|}
\hline \multicolumn{1}{|c|}{ N. $^{\circ}$ bueyes } & Propietarios & $(\mathbf{\%})$ & N.o de bueyes & (\%) \\
\hline $\mathbf{4}$ & 18 & 13,33 & 72 & 16,59 \\
\hline $\mathbf{5}$ & 17 & 12,59 & 85 & 19,58 \\
\hline $\mathbf{6}$ & 6 & 4,44 & 36 & 8,29 \\
\hline $\mathbf{7}$ & 9 & 6,66 & 63 & 14,52 \\
\hline $\mathbf{8}$ & 4 & 2,96 & 32 & 7,37 \\
\hline$\geq \mathbf{1 0}$ & 2 & 1,48 & 23 & 5,3 \\
\hline TOTAL & $\mathbf{1 3 5}$ & $\mathbf{9 9 , 9 7}$ & $\mathbf{4 3 4}$ & $\mathbf{9 9 , 9 9}$ \\
\hline $\mathbf{4 - > 1 0}$ & $\mathbf{5 6}$ & $\mathbf{4 1 , 4 6}$ & $\mathbf{3 1 1}$ & $\mathbf{7 1 , 6 5}$ \\
\hline
\end{tabular}

Un perfil parecido presentan los mayores propietarios de Mengabril hacia mediados del siglo Xvi. En 1548 se van a redactar unas ordenanzas para esta localidad en un contexto de claro enfrentamiento de intereses entre un colectivo reducido de campesinos enriquecidos y el resto de la población ${ }^{26}$. Su número es reducido. Suponen al menos una decena en una población con doscientos vecinos. Este grupo, sin duda, posee varias yuntas

25 A. Ch. Vallalladolid, Reales Ejecutorias, caja 13, n. ${ }^{\circ} 18$.

26 Un conflicto de intereses muy similar entre los mayores propietarios se produce en Andújar: Rodríguez Molina, «Inicios de la expansión del olivar en Jaén», p. 285. 
de bueyes. Se oponen a que solo pueda llevarse un buey holgón a la dehesa boyal, porque eso perjudica a los que labran con «dos o tres yuntas». Este colectivo se caracteriza por su posición superior a la de los simples labradores y por la posesión de ganado menudo. Se alude a ellos como «labradores e señores de ganados» o se indica que son «señores de ganado y tienen puercos y ovejas ${ }^{27}$.

Guareña y Mengabril quizás representen dos modelos diferentes. Este grupo enriquecido parece tener un peso considerablemente superior en la primera localidad. El colectivo con cuatro o más bueyes representa el $14,58 \%$ de la población documentada para Guareña en 1532. Su peso real posiblemente sería más elevado. En Mengabril, este grupo parece tener un menor desarrollo.

Los datos disponibles sobre propiedades agrarias son extraordinariamente parcos y no podemos relacionarlos con la cabaña boyal. Diego Verdión, alcalde pechero en 15411542, disfrutaba de un nivel económico importante; es un buen ejemplo de este sector de labradores acomodados. En 1545, señalaba entre sus propiedades, aunque las asignaba a sus hijos, quizás para evitar responsabilidades económicas y porque procediesen de anteriores matrimonios, 17-18 fanegas de sembradura ${ }^{28}$. Diego Verdión se casó tres veces. Su tercera mujer, Ana Sánchez, con la que convivía en la fecha indicada, aportó como dote matrimonial una huerta, un majuelo y un asno "prieto». En el inventario de propiedades se ańade un buey. Se alude, igualmente, a tres muchachas que debe casar, "que de ellas no me an de pedir soldas sus agüelos ni maridos quellas tengan ni otros por ellas». Se trata, sin duda, de huérfanas que desempeñan una actividad laboral no precisada. Esta información es significativa sobre todo en términos cualitativos, denotando el importante nivel de la pareja y su capacidad para ejercer cierta beneficencia social y utilizar mano de obra extrafamiliar ${ }^{29}$. Conocemos mejor las propiedades de otra esposa anterior, Mari Sánchez. Esta aportó, avanzado el primer cuarto del siglo XVI o a principios del segundo (en 1545, su hijo Rodrigo Alonso Zalameano tenía más de catorce y menos de veinticinco años), una dote valorada en sesenta mil maravedís «entre los quales heran veynte e seys hanegas de tierra, diez de ellas en las Roças de los Rengeles... e çinco bueyes e çinquenta hanegas de trigo y otros bienes ${ }^{30}$. Calcula Rodrigo Alonso que, durante el matrimonio, los bienes de la pareja se incrementaron en otros sesenta mil maravedís, por lo que solicitó de su padre noventa mil. En el inventario de propiedades de Mari Sánchez, realizado en 1545 y que debía corresponder al momento de su muerte, se enumeran 18,5 fanegas de sembradura y dos tierras, dos bueyes y un novillo ${ }^{31}$. Los datos relativos a Mari Sánchez son de extraordinario interés. Para valorar la dote, hay que considerar que un buey podía valer mil doscientos maravedís hacia 1508 y tres mil hacia $1540^{32}$. La disponibilidad inicial de cinco bueyes sitúa a la pareja en el

27 Clemente Ramos, Julián. «Ordenanzas y conflictividad intracampesina en Mengabril (1548)». En Castilla y el mundo feudal. Homenaje al profesor Julio Valdeón. Valladolid, 2009, vol. 3, pp. 243-244.

28 AGS-CR, leg. 140, n. ${ }^{\circ} 4-3$ b, fol. 63r-v.

AGS-CR, leg. 140, n. ${ }^{\circ}$ 4-3b, fols. 156r-158v.

AGS-CR, leg. 140 , n. ${ }^{\circ} 4-3$ b, fol. 164 r.

AGS-CR, leg. 140, n. ${ }^{\circ} 4-3$ b, fols. $165 \mathrm{v}-166 \mathrm{r}$.

32 A. G. Simancas, Cámara de Castilla, Pueblos, leg. 11, n. ${ }^{\circ}$ 368, fol. 2v; AGS-CR, leg. 140, exp. 2, fol. 161v. 
grupo de labradores acomodados que cuentan con más de una yunta. La pareja, según su hijo, acumuló un patrimonio importante durante su matrimonio. Aunque no tengamos certeza alguna sobre el nivel de riqueza de Diego Verdión, al menos dos de sus mujeres pertenecen a los niveles elevados del campesinado por las propiedades y bueyes poseídos y la disponibilidad de sirvientas.

Aunque de condición hidalga, el nivel económico de Gonzalo Ruiz, regidor de Medellín en 1541-1542, se aproximaría a este grupo de labradores enriquecidos. En 1545, contaría con 3-4 bueyes y alrededor de una veintena de fanegas de sembradura. A una hija le había entregado en dote diez-doce fanegas. Parece contar igualmente con 50-60 vacas ${ }^{33}$.

Este colectivo que dispone de un número importante de bueyes se caracteriza por una importante y complementaria dedicación ganadera ${ }^{34}$. Es llamativo que en las prendas de 1488 aparece una correlación positiva entre la posesión de bueyes y de otras especies ganaderas. Los que poseen un buey cuentan con 8,8 cabezas porcinas; un único propietario de dos bueyes solo dispone de cuatro puercas; los que tienen 5-8 bueyes alcanzan las 40,83 cabezas; y dos propietarios con siete y ocho bueyes superan las sesenta ${ }^{35}$. Estos datos tienen un extraordinario interés al establecer una relación clara y precisa entre la propiedad boyal, elemento central para definir el nivel campesino, y porcina. Conocemos la estructura de su propiedad ${ }^{36}$. La información indicada nos permite relacionarla con los niveles patrimoniales campesinos y apreciar su significado social, no menos importante que el económico. La mayor parte de la cabaña porcina, que tuvo una importancia extraordinaria en la tierra de Medellín y debió constituir uno de los elementos más relevantes del comercio local, debió estar en manos de estos labradores acomodados que han encontrado en esta actividad una dedicación complementaria de clara orientación mercantil. El modelo de la cabańa porcina se mantiene en sus líneas generales para el periodo 1525-1550. Dominan las cabañas de 10-19 y más de cuarenta cabezas (47,73\% y 43,18\% respectivamente). Las de $20-39$ solo alcanzan un $6,82 \%$, sin que tengamos para ello una explicación satisfactoria.

En este colectivo de labradores con pequeñas cabañas de ganado porcino u ovino, aparece una especialización laboral clara. Los miembros de la familia y los domésticos más jóvenes se dedican al cuidado del ganado ${ }^{37}$. Algunos ejemplos son muy ilustrativos. Francisco Gallego «anduvo por el dicho término, siendo muchacho [Valdetorres, c 1509],

33 AGS-CR, leg. 140, n. ${ }^{\circ} 4-3$ b, fols. 64v-65r y 149v, y n. ${ }^{\circ}$ 2, fol. 149v. Su mujer Juana de Escobar, ya fallecida en 1545, aportó una dote valorada en doscientos mil maravedís, en la que se incluían diez fanegas de sembradura y $1 / 8$ de la aceńa de Martel (AGS-CR, leg. 140, n. ${ }^{\circ} 4-3 b$, fol. 147r).

34 Carrasco Tezanos, La sociedad campesina en la sierra de Guadarrama, p. 144, presenta una situación similar pero en un contexto de montaña con un mayor peso de los patrimonios ganaderos.

35 Clemente Ramos, Julián. «Notas sobre la ganadería estante de Medellín (1488)». En la España Medieval, 2008, vol. 31, pp. 157-158.

36 Sobre el particular, Clemente Ramos, «La ganadería en Medellín (1450-1550)», aptdo. 1.5.

37 Rodríguez Llopis, Miguel. Señoríos y feudalismo en el reino de Murcia. Los dominios de la Orden de Santiago entre 1440 y 1515. Murcia, 1984, p. 178; VICIANO, Els peus que calciguen la terra, pp. 153-154; VAssberg, David E. "Juvenalia in the rural work force of sixteenth century Castile». The Journal of Peasant Studies, 1983, vol. II, n. ${ }^{\circ} 1$, pp. 62-75. 
con puercos de su padre...; y después que fue mançebo e casado, arando e senbrando en el dicho término ${ }^{38}$. Entre los hijos, prácticamente en tres de cada cuatro ejemplos documentados la actividad pastoril está desarrollada por miembros con una edad de entre diez y veinte ańos. Posteriormente, esta actividad, aunque puede mantenerse, pierde importancia. A partir de los veinte años, la dedicación agraria es más frecuente. Hay que considerar que estamos ante explotaciones en las que esta actividad es prioritaria.

CuAdro 4.- Explotaciones campesinas: dedicación pastoril (1450-1550).

\begin{tabular}{|l|c|c|c|c|}
\hline \multirow{2}{*}{ Periodo } & \multicolumn{4}{|c|}{ Edad } \\
\cline { 2 - 5 } & \multicolumn{3}{|c|}{ Hijos } & \multicolumn{2}{c|}{ Domésticos } \\
\cline { 2 - 5 } & $\mathbf{1 0 - 1 9}$ & $\mathbf{2 0}$ & $\mathbf{1 0 - 1 9}$ & $\geq \mathbf{2 0}$ \\
\hline $\mathbf{1 4 5 0 - 1 5 0 0}$ & 5 & 1 & 2 & 1 \\
\hline $\mathbf{1 5 0 1 - 1 5 5 0}$ & 6 & 3 & 9 & 9 \\
\hline ToTAL & $\mathbf{1 1}$ & $\mathbf{4}$ & $\mathbf{1 1}$ & $\mathbf{1 0}$ \\
\hline TотAL (\%) & $\mathbf{7 3 , 3 3}$ & $\mathbf{2 6 , 6 7}$ & $\mathbf{5 2 , 3 8}$ & $\mathbf{4 7 , 6 2}$ \\
\hline
\end{tabular}

\section{CAMPESINOS MEDIOS: LOS LABRADORES}

El grupo de campesinos medios que dispone de una yunta de bueyes no queda bien definido. Sin duda, debió ser un colectivo de considerable importancia económica, social y también demográfica. En las prendas de 1488, reiteradamente citadas, los propietarios de una yunta de bueyes (2-3 bueyes) suponen casi un tercio de los propietarios de bueyes $(30,49 \%)$ y poseían algo más de un quinto de la cabaña $(22,61 \%)^{39}$. Estos datos definen fundamentalmente la situación de Guareña y no tendría que reproducirse de forma exacta en los demás núcleos de población.

En otras aldeas, diversos indicios parecen indicar una menor concentración de la cabańa boyal y con ello un peso superior de los simples labradores. En Mengabril, la mayoría que acumula bueyes y ganado parece una minoría. Es muy posible que este colectivo no llegase a un $10 \%$ de la población y posiblemente se situaría por debajo. Por ello, los labradores, es decir, los propietarios de una yunta o poco más, serían el colectivo más numeroso y el que poseería la mayor parte de la cabaña local estimada en medio millar de ejemplares $(2,5 \text { bueyes/vecino })^{40}$.

Es sintomático que en las prendas realizadas sobre oficiales de Don Llorente, en 1538, a dos de ellos se les tome dos bueyes; a uno, cuatro; y a otro una vaca y una burra ${ }^{41}$. $\mathrm{Al}$ menos en el ámbito del poder concejil, los labradores parecen estar bien representados.

En el caso de Villar de Rena, que hemos estudiado recientemente, también parece haber un importante grupo de labradores. En una aldea con cincuenta y seis vecinos

38 AChGra, caja 31, n. ${ }^{\circ}$ 1, fol. 482r.

39 Clemente Ramos, «Notas sobre la ganadería estante de Medellín», p. 155.

40 Clemente Ramos, «Ordenanzas y conflictividad intracampesina», p. 243.

41 AGS-CR, leg. 230, n. ${ }^{\circ}$ 6, fol. $15 \mathrm{v}$. 
pecheros en 1532, en 1543 cincuenta y dos vecinos pagan penas por el ramoneo de sus bueyes. El grupo con cuantías medias es el mejor representado y los que satisfacen las mayores cantidades solo suponen algo más de una quinta parte $e^{42}$. Todo nos hace pensar que la base social, económica y demográfica de Villar de Rena está representada por los labradores con una yunta de bueyes, si bien su modelo económico (se han comunalizado las hojas de cultivo) nos obliga a relativizar su significación en el conjunto de la tierra de Medellín.

El caso de Miajadas es también de gran interés, sobre todo por ser una de las aldeas más pobladas de la tierra y contar con élites campesinas consolidadas. No tenemos información directa sobre la propiedad de bueyes, pero sí sobre los alcaceres. Estos espacios cercados de cultivo se desarrollan en el ejido a partir de mediados del siglo XV o como muy tarde en el último cuarto de este siglo. El crecimiento agrario ha producido la insuficiencia de la dehesa boyal. Los alcaceres se destinan a la alimentación de este ganado. En el ejido se han debido crear unas trescientas cercas, de las que tenemos información directa de unas doscientas. Sobre ciento seis propietarios de los que se conserva el correspondiente pleito, solo seis se han apropiado de dos (cuatro) o tres (dos) cercas. En torno al 95\% de los vecinos que disponen de alguna solo cuentan con una ${ }^{43}$. Esto nos hace pensar en un reparto relativamente equitativo del ganado boyal. En 1540, Sancho y Rodrigo de Orellana alquilaron diez yuntas para labrar Cuadrado. Recurrieron a un número indeterminado de propietarios, entre los que se encontraban un tal Vázquez (cuatro bueyes), Bartolomé Pérez (dos) y Fernando Alonso Zapardiel (dos) ${ }^{44}$.

Aunque no estamos en condiciones de precisar en términos cuantitativos la importancia de los simples labradores, es decir, de aquellos campesinos que disponían de una yunta de bueyes, no cabe duda de que tenían una elevada significación económica. En el caso de Guareńa lo hemos podido precisar, con las reservas correspondientes, para finales del siglo xv. En otras aldeas, aunque sin datos cuantitativos, parece que la propiedad boyal estaría aún más repartida y el peso demográfico de este colectivo no sería en ningún caso menor. Retengamos simplemente la idea de que entre finales de la Edad Media y comienzos de la Moderna, los labradores son un grupo importante demográfica, social y fiscalmente ${ }^{45}$.

Los labradores medios no parecen caracterizarse por la posesión de un número importante de cabezas de ganado, como sucede con aquellos más acomodados. La imagen que nos transmite el pleito que se desarrolla en Mengabril sobre sus ordenanzas es muy clara. Frente a los "labradores y señores de ganado" acomodados, los simples labradores no tienen especiales intereses pecuarios. En 1488, entre los propietarios de

42 Clemente Ramos, Julián. "El régimen agrario de Villar de Rena a mediados del siglo Xvi». Rivista di Storia dell'Agricoltura, 2012, vol. LII, n. ${ }^{\circ}$ 2, pp. 14-15.

43 AGS-CR, leg. 230, exp. 1, fols. 129r-130r.

44 AGS-CR, leg. 231, exp. 10, fol. 44r.

45 Domínguez Vinagre, Alfonso. El señorio de Salvatierra en la baja Edad Media. Badajoz, 2009, p. 227, señala cómo en 1499 en esta población había 382 vecinos de los cuales 244 (63,87\%) eran pecheros de cuantía, situación próxima aunque no estrictamente equiparable a la de los labradores. 
puercos, los que cuentan con dos o un buey, salvo para un caso (20 cabezas), solo poseen 6 cabezas o menos ${ }^{46}$. La imagen que nos transmiten otras informaciones apunta en la misma dirección.

El pleito entre Diego Ruiz y el conde de Medellín nos presenta un fresco lleno de detalles sobre los labradores y su consideración social. La parte condal intenta presentarlo como un «labrador pechero de baxa suerte e muy pobre» o como «onbre muy pobre labrador, de los más pobres y baxos que ay en el lugar de Don Benito». Su homónimo y vecino, igualmente de Don Benito, indica que cuenta con «biñas e bueyes e labrança como los onbres onrados». Sabemos que tenía dos bueyes y una casa. Juan Ramos lo define acertadamente, dentro de los niveles campesinos, como «honbre pechero e de mediana suerte» que "no es rico». Estima su hacienda, posiblemente en términos realistas, en quince-veinte mil maravedís (la parte condal la valora solo en seis mil). $\mathrm{Su}$ posición económica distaba de ser desahogada. Hasta 1534 había sido redero del conde, recibiendo un acostamiento de cuatro mil maravedís y veinticuatro fanegas de trigo. Anteriormente había sido cardador ${ }^{47}$. Uno de sus hijos era mozo de soldada en casa de Juan Blázquez, vecino de Don Llorente. No parece que Diego Ruiz contara con ningún capital ganadero relevante, si verdaderamente contaba con alguno ${ }^{48}$. Estos datos, no especialmente numerosos pero sí de extraordinario interés, muestran una enorme complejidad de las realidades sociales. Dentro de su condición de labrador, Diego Ruiz parece disponer de una situación económica ajustada o al menos ha desarrollado, quizás por necesidad, otras dedicaciones profesionales como fuentes adicionales de ingresos. A ello se une que, al igual que las familias más necesitadas, hacía contratar a su hijo por algún campesino acomodado.

Sabemos poco sobre aquellos que poseían un solo buey. La labranza se hace siempre con yuntas y por ello se veían obligados a establecer acuerdos, recibir prestado o alquilar bueyes ${ }^{49}$. Nuestras fuentes permanecen mudas sobre esta realidad. Este colectivo sólo aparece explícitamente en las prendas de 1488. En Guareña (1488), suponen casi un tercio de los propietarios de bueyes $(29,08 \%)$, porcentaje muy similar a los que poseen dos-tres (30,49\%). En Valdetorres, con datos muy parciales, casi todos se incluyen en este grupo ${ }^{50}$. No se trata de un colectivo sin importancia. Sin duda, serían muchos los que poseían un solo buey y se veían obligados a actuaciones que nuestras fuentes no

46 Clemente Ramos, «Notas sobre la ganadería estante de Medellín», p. 159; A. Ch. Valladolid, Reales Ejecutorias, leg. 13, n. ${ }^{0} 18$.

47 Coronas VIDA, Luis Javier. La economía agraria en las tierras de Jaén (1500-1650). Granada, 1994, p. 129, ha documentado igualmente el desempeño de trabajos adicionales como hortelano o carretero por parte de labradores en Linares a finales del siglo Xv.

48 AGS-CR, leg. 87, n. ${ }^{\circ} 14$, fols. $247 \mathrm{v}-265$ r; y leg. 585 , n. ${ }^{\circ}$ 7, fols. $12 \mathrm{v}-20 \mathrm{r}$.

49 Conocemos mal el mercado de los bueyes y las estrategias campesinas (alquiler, copropiedad o asociación) utilizadas para dotarse de estos animales en los casos necesarios: Rodríguez GaLdo, M. ${ }^{a}$ Xosé. Señores y campesinos en Galicia. Siglos XIV-XVI. Santiago, 1976, p. 133; Bernal Estévez, Ángel. El concejo de Ciudad Rodrigo y su tierra durante el siglo XV. Salamanca, 1989, p. 371; BRumonT, Francis. "L'exploitation paysanne en Vieille-Castille à la fin du XVI ${ }^{e}$ siècle». En Congreso de Historia Rural. Siglos XV al XIX. Madrid, 1984, p. 149.

50 Clemente Ramos, «Notas sobre la ganadería estante de Medellín», p. 155. 
iluminan debidamente. Aunque no de modo exclusivo, este grupo sería el que estuviera más vinculado al alquiler de estos animales. Esta actividad se encontraba plenamente desarrollada en toda la región y, sin duda, respondía a una necesidad real ${ }^{51}$.

El alquiler de bueyes está presente en las fuentes medellinenses. En las ordenanzas de Don Benito de 1548, no así en las de Mengabril, se alude a esta práctica. La información es del máximo interés. Don Benito, y quizás la tierra de Medellín en su conjunto, es deficitaria en la producción de ganado de labor. Se toman medidas para facilitar la cría. A mediados del siglo xvi, la compra de animales de otras comarcas era habitual. Igualmente, también se alude a «los bueys que los vezinos deste lugar de Don Benito traxeren arrendados de fuera parte» ${ }^{52}$. Esta actividad sería estrictamente necesaria para aquellos que, por disponer de un único animal, tenían la necesidad ineludible de completar una yunta. Se abren, por tanto, mecanismos y posibilidades de actuación para este grupo, cuya situación real y casuística concreta ignoramos pero que intuimos poco cómoda e inestable.

\section{Asalariados y POBRES}

Por debajo de la condición de labrador y con poca o ninguna propiedad agraria aparece todo un colectivo numeroso que solo en algunos casos percibimos con cierta claridad. Sin duda, las situaciones serían muy variadas. Algunos tendrían alguna dedicación agraria y otros basarían su subsistencia en el trabajo asalariado. Un sector importante dispondría de medios muy limitados y podrían considerarse pobres en un sentido estricto. Para estos, los derechos vecinales tendrían un valor especial dentro de una auténtica economía de la pobreza.

\subsection{Domésticos y criados}

En una sociedad rural profundamente estratificada y con sectores campesinos enriquecidos, se desarrolla una demanda de trabajo asalariado. Esta presenta un doble perfil, con domésticos y contratos temporales. Los sectores menos favorecidos pueden disminuir de este modo el número de bocas que alimentar o conseguir unos ingresos adicionales dentro de su economía necesariamente creativa e informal. Nuestra información es desigual. Nos permite trazar el perfil de criados y domésticos, aunque no calibrar su peso social. Para los que tienen contratos de corta duración disponemos de una información dispersa que nos permite documentar poco más que su existencia.

El término criado se utiliza de modo generalizado para designar al colectivo con contratos de larga duración. Este término, con cierta connotación doméstica, se aplica

51 Clemente Ramos, Julián. "Técnicas y usos agrarios en Extremadura (siglos XIII-XvI)». Bullettino Istorico Italiano per il Medio Evo, 2007, vol. 109, n. ${ }^{\circ}$ 2, pp. 10-11.

52 Bernal Estévez, Ángel. «Don Benito en la primera mitad del siglo XVI». Boletín de la Real Academia de Extremadura de las Letras y las Artes, 2002, vol. XII, p. 271. 
también a vaqueros y empleados de explotaciones ganaderas. A veces se usan otras denominaciones como mozo o mozo de soldada o de caza ${ }^{53}$, que denotan juventud, meseguero $^{54}$ o "apaniaguado» ${ }^{55}$. No debemos olvidar que entre los domésticos hay dos grupos claramente diferenciados. Los criados de los grupos rurales enriquecidos desarrollan siempre funciones productivas, mientras los vinculados a sectores de la nobleza medellinense ofrecen una situación más diversificada. No siempre podremos considerar a estos últimos grupos rurales en sentido estricto, dada su relación muchas veces escasa con la actividad productiva.

Hay dos rasgos que definen a los criados o domésticos: la residencia en casa del "amo» ${ }^{56}$ y su modestia/pobreza económica. En algunos casos se indica el primero de ellos de modo explícito. Juan Blázquez, vecino de Don Llorente, «tenía en su casa» por mozo de soldada a un hijo de Diego Ruiz. De Antón se indica «que bive con Savastián Domínguez». Felipe Pérez y Nájera duermen en casa de sus respectivos amos ${ }^{57}$. Sobre estos dos personajes, relacionados con un delito de robo, la información disponible es muy interesante sobre la libertad con la que podían moverse al menos algunos criados en casa de sus amos. Es posible que esta situación se ajustara más a aquellos vinculados a miembros de la oligarquía local. Nájera, criado de Juan de Godoy, consigue convencer a Felipe Pérez, criado de Alonso Pérez, para dormir ambos en casa de su amo aprovechando los recursos disponibles. Realizan diversos robos de trigo e incluso de una cota de mallas. Utilizan los costales de la casa prestados. Estos robos debieron hacerse con cierta facilidad abusando de la proximidad y confianza, porque "todas [las puertas] estavan abiertas». Parte del beneficio lo perdieron jugando a los naipes. En connivencia con criados de otros personajes también robaron un cántaro de vino en casa de Alonso Flores, para lo que contaron con Bartolomé, "criado de Gonçalo Dávila, que a la sazón era criado de Alonso Flores». En este caso, al no participar criados directos de Alonso Flores, «saltaron por los corrales» y se lo bebieron «en casa del dicho Contreras» ${ }^{58}$. La imagen que nos transmiten estas actuaciones, llamativas por su excepcionalidad, es la confianza existente entre amos y domésticos y la relativa libertad con que estos se mueven dentro de la casa en que viven. Esta confianza estaría avalada por una relación en muchos casos larga. No extraña por ello que aparezcan en las mandas testamentarias o que se beneficien de ayudas que superan el ámbito estrictamente económico. Francisco David, vecino de Miajadas, mandó en su testamento a Francisca, una criada suya huérfana, «sesenta ducados [22.500 mrs.] y una

53 AGS-CR, leg. 230, n. ${ }^{\circ}$ 6, fols. 200v-201r; y leg. 585, n. 7, fol. 31r («este testigo [Juan Blázquez, $v^{\circ}{ }^{\circ}$ de Don Llorente] tenía en su casa por moço de soldada a un hijo del dicho Diego Ruiz»); AGS-CR, leg. 230, n. ${ }^{\circ}$ 6, fol. 200v («son moços de caça [Felipe y Nájera] e questán en casa de Alonso Álvarez, e que no les conoçe bienes ningunos»).

54 AGS-CR, leg. 231, n. ${ }^{\circ} 10$, fol. 3r.

55 AGS-CR, leg. 663, n. ${ }^{\circ}$ 27, fol. 86v.

56 En relación con criados o similares, se utiliza este término para designar a sus contratantes (AGSCR, leg. 663, n. ${ }^{\circ} 27$, fol. 86v, a. 1501; leg. 230, n. ${ }^{\circ} 4$, fol. 25v, a. 1539; y leg. 230, n. ${ }^{\circ}$ 6, fol. 199r).

57 AGS-CR, leg. 585, n.o 7, fol. 31r, a. 1534-35; leg. 231, n.o 1 bis, fol. 5r; leg. 230, n. ${ }^{\circ}$ 6, fol. 199r («estando durmiendo este confesante [Felipe Pérez] en casa de Alonso Álvarez, su amo, Nájara su collaço le dixo que se fuese a durmir con él a las dichas casas de Juan de Godoi»).

58 AGS-CR, leg. 230, n. ${ }^{\circ}$ 6, fol. 199r. 
taça de plata» (a. 1533-1543). Contreras crió a algunos de los hijos de Juan de Paredes, su criado $^{59}$. Las relaciones amos/criados superan el mero ámbito económico y se sustentan, sin duda, en vínculos mantenidos durante largos periodos de tiempo.

La condición de estos criados, que alivian las demandas alimenticias de sus familias de origen, es muy modesta. La escasa información disponible incide en la falta total de propiedades. Sin duda, este grupo se nutre de personas que están en la pobreza. A Juan de Prado, criado de Álvaro de Alburquerque, al que sigue a Villanueva, un testigo le tiene "por onbre pobre que no le conosçe vienes ninguno» ${ }^{60}$. En términos prácticamente literales se habla de los mozos de caza Felipe y Nájera ${ }^{61}$. Algunos criados del conde responden al perfil de "pechero llano e pobre» ${ }^{62}$. De Juan de Paredes se indica, de forma más detallada, que es "onbre pobre, vil e reez e beodo contino" ${ }^{63}$.

La información sobre las actividades desarrolladas por domésticos y criados es muy escasa. Sin duda, entre ellas tenían importancia las actividades pastoriles, prácticamente exclusivas entre los más jóvenes y ampliamente documentadas por su vinculación con la montanera. Las labores agrarias quedan en la penumbra salvo de modo muy genérico. Los domésticos y criados que no alcanzan la veintena, los «muchachos» que no llegan a «mozos», se dedican junto a los miembros más jóvenes de la familia a cuidar ovejas y, sobre todo, puercos (cf. cuadro 4). La actividad laboral se inicia en torno a los diez ańos. Es llamativo que la memoria de muchos testigos procesales se inicie a esta edad. Sin duda, a partir de este momento tomarían un contacto preciso con el entorno y las realidades rurales. Son los muchachos (10- 15 ? años) y los mancebos o jóvenes. Francisco Martín alude a cuando era «mançebo de hasta veynte años» ${ }^{64}$. Juan Zambrano (c 1482) y Diego Mateos (c 1525) siendo «muchachos» guardaron puercos ${ }^{65}$. Alonso Martín, vecino de la cercana aldea de San Pedro de Mérida, es un ejemplo ilustrativo. Hacia 15011502 se fue a vivir a Guareńa, contando quince años, y estuvo tres años guardando ganado en los baldíos de tres «amos» diferentes ${ }^{66}$. A partir de la veintena, las actividades desarrolladas se amplían. Las labores agrarias adquieren una importancia creciente. Ya hemos aludido a ello en relación con los propios hijos a partir de la veintena. El citado Juan Zambrano estuvo, "después que fue mançebo e casado, arando» ${ }^{67}$. Un hijo de Diego Ruiz estaba como "moço de soldada", lo que parece indicar actividades diversas, en casa de Juan Blázquez, vecino de Don Llorente ${ }^{68}$. Antón, que vivía con Sebastián Domínguez, vecino de Guareña, en diciembre de 1539 "por su mandado fue a caça de perdizes» ${ }^{69}$. Quizás este ejemplo es el más claro de la diversidad de tareas que podían desempeñar los

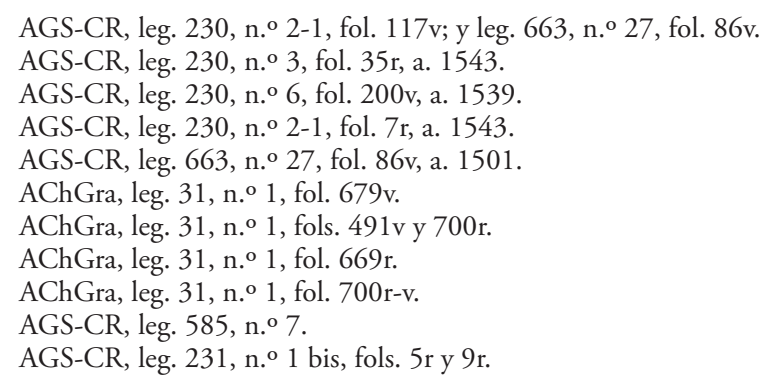


criados. Algunos, o quizás bastantes de ellos, dejarían de tener esta condición al superar la veintena, momento en que entran en edad casadera.

\subsection{Pastores}

La actividad pastoril fue muy importante en la tierra de Medellín. Una gran parte de la jurisdicción estaba ocupada por dehesas, especialmente, y otros espacios pecuarios. A los pastores en sentido estricto se unían aquellos que tenían en la actividad pastoril una dedicación preferente o exclusiva en su calidad de adolescentes o criados/domésticos.

La demanda de pastores era relativamente abundante en la tierra de Medellín, pero no todos eran vecinos de la jurisdicción. Los pastores de los serranos eran contratados en su mayor parte en los lugares de origen. Disponemos de muy pocos datos al respecto. Generalmente, en los pleitos se interroga a los trashumantes y se alude en pocas ocasiones a sus pastores. En los limitados casos en que conocemos su vecindad proceden, al igual que las cabañas, de tierras segovianas (Hontoria, Lozoya, Sonsoto o Pinilla) ${ }^{70}$. En sentido contrario solo documentamos a Hernán Martín, vecino de la aldea emeritense de San Pedro, que entre 1512 y 1521, aproximadamente, fue vaquero del serrano Francisco de Ribera. También lo fue del propietario local Juan Flores ${ }^{71}$. La situación probablemente no sería diferente en las cabañas riberiegas, sobre las que no conocemos la identidad de ningún pastor. Es llamativo que en el pleito que enfrenta a Medellín y la Mesta a principios del siglo XVI aparezca un importante número de testigos de los términos comarcanos de Mérida, Alange, Magacela y Montánchez y de la aldea limítrofe de Escurial ${ }^{72}$. Muchos de ellos, probablemente, han cuidado ganado en la jurisdicción medellinense.

La documentación del monasterio de Guadalupe nos presenta datos de gran interés. Aproximadamente un tercio de sus pastores se reclutan en la tierra de Medellín, otro en las inmediaciones (Escurial o Búrdalo) y, finalmente, otro en las proximidades de Guadalupe (Logrosán).

CuAdro 5.- Vaqueros del monasterio de Guadalupe (1450-1550): origen geográfico.

\begin{tabular}{|l|l|c|c|}
\hline \multicolumn{2}{|c|}{ Vecindad } & \multicolumn{2}{c|}{ N.o } \\
\hline \multirow{3}{*}{ Tierra de Medellín } & Miajadas & 6 & 7 \\
\cline { 2 - 3 } & Guareńa & 1 & $(35 \%)$ \\
\hline \multirow{4}{*}{ Otras vecindades } & Logrosán & 7 & \\
\cline { 2 - 3 } & Escurial & 5 & 13 \\
\cline { 2 - 3 } & Búrdalo & 1 & \\
\hline
\end{tabular}

70 AGS-CR, leg. 64, n. ${ }^{\circ}$ 7-5.

1 AChGra, 31, n. ${ }^{\circ}$ 1, fol. 674v.

72 Clemente Ramos, «La ganadería en Medellín (1450-1550)», aptdo. 1.2; AGS-CR, caja 64, n. 7. 
La información disponible sobre los pastores de Guadalupe nos permite esbozar un perfil de este colectivo. Al contrario que en el ámbito doméstico, donde domésticos o miembros jóvenes de la familia desarrollan una actividad pastoril, la entrada en este colectivo no se realiza hasta la madurez. El inicio de este trabajo no comenzaría de modo habitual hasta la veintena. En un caso, parece haberse iniciado un poco antes. Blasco Martín, que debió nacer hacia 1481 (contaba con cincuenta y un años en 1532), empezó a trabajar de modo ininterrumpido para el monasterio de Guadalupe hacia 1495 («fue vaquero del dicho monesterio treinta e ocho ańos» ${ }^{73}$. Tenemos algún otro caso en que se mantiene la dedicación de pastor a lo largo de toda la vida. Alejo González declara que «toda su vida a sido vaquero dende que sería de hedad de veinte años» ${ }^{74}$. No sabemos si los demás mantuvieron esta dedicación de modo permanente. Los testigos se limitan a indicar generalmente el tiempo que estuvieron al servicio del monasterio. Lo normal es que la relación laboral se mantenga durante varios años, acercándose en la mayor parte de los casos a una década. Sobre trece casos en que tenemos información, en diez estuvieron como pastores del monasterio de Guadalupe entre siete y diez años. En tres, la relación se mantuvo entre cinco y dos ańos ${ }^{75}$. La dedicación pastoril sería en muchos casos larga.

Poco sabemos de los salarios y condiciones laborales de este colectivo. La documentación guadalupense nos suministra alguna información que podría aplicarse en mayor o menor medida a los vaqueros de la jurisdicción, que desarrollan su trabajo de forma prácticamente exclusiva en las dehesas. Los vaqueros de Trujillo y Medellín, donde eran especialmente importantes, recibían habitualmente a finales del segundo tercio del siglo XV «II annojos, e XXV vacas escusadas, e sayal e cueros». Se nos indica con precisión el salario de los vaqueros de Guadalupe (casi exclusivamente de la jurisdicción de Medellín) en $1462^{76}$ :

Cuadro 6.- Monasterio de Guadalupe: salario de los pastores (1462).

\begin{tabular}{|l|c|c|l|}
\hline \multicolumn{1}{|c|}{ Oficio } & Vacas excusadas & Mrs. & \multicolumn{1}{c|}{ Otros } \\
\hline Mayoral & \multicolumn{3}{|c|}{ según acuerdo «ca uno meresçe más que otro» } \\
\hline Conocedor & 40 & 20 & $\begin{array}{l}10 \text { varas de sayal, } 1 / 2 \text { cuero curtido para suelas, } \\
2 \text { añojos }\end{array}$ \\
\hline Ropero & 20 & - & 12 varas de sayal, $1 / 2$ cuero, 2 añojos \\
\hline Vaquero & 20 & - & 8 varas de sayal, $1 / 2$ cuero, 1 ańojo \\
\hline
\end{tabular}

Juan Rubio fue mayoral de las vacas del monasterio de Guadalupe en los últimos ańos de su vida. En el momento de su muerte, acaecida en 1499, recibía un salario de

73 AChGra, caja 1.369, n. ${ }^{\circ}$ 9-1, fol. 54v.

74 AChGra, caja 1.353, n.o 9-3, fol. 59v.

75 Información obtenida en AChGra, caja 1.330, n. ${ }^{\text {os }} 7-1$ y 7-2; caja 1.353, n. ${ }^{\text {os }} 9-1$, 9-3 y 9-4; y caja 1.369, n. ${ }^{\circ} 9-1$.

76 Cabanes Catalá, M. a Luisa (dir.). Libro de los oficios del monasterio de Nuestra Señora de Guadalupe. Badajoz, 2007, vol. I, p. 102. 
4.887,5 maravedís ${ }^{77}$. No sabemos si disfrutaba de otros beneficios. En todo caso, se trata de una cantidad muy superior a la manejada para los conocedores.

Las vacas excusadas de los vaqueros, parte sustancial de su salario, tenían una gran importancia. En 1479, el monasterio de Guadalupe tenía en sus dehesas de Medellín 1.297 vacas propias, 343 vacas de los vaqueros y 220 vacas «ervajeras» ${ }^{78}$. No sabemos con cuántos vaqueros contaba ese año el monasterio. Las vacas escusadas representaban el $18,44 \%$ del total de la cabaña bovina, casi una quinta parte.

El monasterio de Guadalupe contaba en 1462 con una cabaña bovina de 2.798 cabezas, en su mayor parte suponemos que en Medellín. Este ganado era cuidado por un mayoral, dos conocedores, tres roperos y treinta y cuatro vaqueros ${ }^{79}$. Resulta de ello un asalariado por cada 69,95 cabezas. Si solo consideramos a los vaqueros, la cifra anterior se eleva a $82,29 \mathrm{cabezas}^{80}$. Merece la pena que reflexionemos sobre estas cantidades. Si se establece una proporción similar para la tierra de Medellín, el equivalente de veintidós mil vacas que pastaban en las dehesas de la jurisdicción, de las cuales la mitad serían estantes, necesitarían del concurso de más de trescientos pastores. Pese a su carácter meramente hipotético, esta cifra nos da idea de la importancia que la actividad pastoril debió tener en la tierra de Medellín y de las posibilidades que se ofrecían a colectivos no siempre sin recursos.

\subsection{Pobres y pobreza}

El concepto de pobre es variable. En algunos supuestos se opone a rico y abarca a casi todo el conjunto social. Se dice de un oficial electo del concejo de Medellín que es «un labrador pobre que, si no trabajase por su persona en su huerta cavando y arando, porque es ortolano, o en otro semejante ofiçio, no mantendría su casa e familia ${ }^{81}$. De otros se dirá que son "pobres e pecheros llanos»" ${ }^{82}$. La condición de labrador o pechero indica la disponibilidad de unos niveles patrimoniales mínimos. Esta acepción es poco operativa por su falta de matices para el análisis de la sociedad rural, pero marca claramente la diferencia entre un limitado número de personas acomodadas y el resto. El término adquiere otro sentido más restringido cuando alude a situaciones de necesidad («muy pobres e neçesitados») o de ausencia de cualquier propiedad («onbre pobre que no le conosçe vienes ninguno») ${ }^{83}$. En este último caso alude o puede aludir a situaciones de pobreza extrema y dificultad para subvenir a las necesidades más perentorias.

77 Clemente Ramos, «Élites rurales en Extremadura», p. 235.

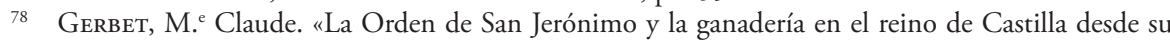
fundación a principios del siglo XVI». Boletín de la Real Academia de la Historia, 1982, vol. CLXXIX/2, p. 268.

79 Cabanes Catalá, Libro de los oficios, I, p. 102; Cerro Herranz, María F. El dominio del monasterio de Santa María de Guadalupe. Estudio de su estructura económica en el siglo xv. Cáceres, tesis doctoral inédita, ¿1988?, vol. II, p. 318.

80 En la zona sevillana, un vaquero llega a guardar entre ciento veinticinco y ciento cincuenta vacas: Carmona Ruiz, M. a Antonia. La ganadería en el reino de Sevilla durante la Baja Edad Media. Sevilla, 1998, p. 397.

81 AGS-CR, leg. 520, exp. 12, fol. 83v, a. 1545.

82 AGS-CR, leg. 230, exp. 2-1, fol. 7r, a. 1543.

83 AGS-CR, leg. 231, exp. 8, fol. 21r, a. 1540; y leg. 230, exp. 3, fol. 35r, a. 1543 (Juan de Prado es considerado, igualmente, como «un onbre muy pobre»). 
El colectivo de pobres ha debido alcanzar un peso importante. Se señala para Don Benito que hay "muchas personas pobres y miserables»" ${ }^{84}$. Situaciones como esta explican el desarrollo de determinados usos que tienen como finalidad facilitar su mantenimiento. Se trata de una realidad muy generalizada en la Castilla bajomedieval hasta el punto de que podemos hablar de una economía de la pobreza. Estos pobres extremos se caracterizan por sus escasas o nulas propiedades.

Ya hemos aludido a la relación pobreza/inexistencia de propiedades. Sin embargo, no sería infrecuente la posesión de algunas cabezas de ganado. En relación con la prohibición de llevar una vaca y una yegua a la dehesa de Remondo, que en el segundo cuarto del siglo Xvi se va a reservar a los bueyes, se alude al impacto que esto tendría en viudas pobres "porque no tenían adonde traer algunas reses que tenían sino en la dicha dehesa de Remondo» ${ }^{85}$. Es posible que estemos ante la cría de bueyes como fuente de obtención de recursos. Esta actividad se sustenta en los derechos comunales, auténtico pilar social y económico de los pobres. Estos derechos vecinales, ante la escasa o nula disponibilidad de propiedades, van a constituir una fuente económica imprescindible que no deja de reflejarse en el ámbito normativo.

Los derechos comunales, de modo general, van a ser imprescindibles para los pobres. La montanera constituye un recurso fundamental. El auxilio de los pobres se convertirá en un argumento central para defender este derecho vecinal frente a la autoridad jurisdiccional ${ }^{86}$. El procurador de Guareńa sostiene en 1539, y será ratificado por los testigos, que "de la dicha bellota de los dichos montes se sustentan e remedian muchas personas pobres e bibdas» ${ }^{87}$. Pobres y otros colectivos acudían a recoger la bellota durante el desacoto en los primeros días de noviembre. Un vecino de Medellín nos dice que en 1543, debido al aprovechamiento abusivo que realizaban los oficiales, labradores y pobres "no an hallado qué coger [bellota]» ${ }^{88}$. Es evidente que este recurso era vital para los diversos grupos rurales, aunque no tenía la misma relevancia para todos. Entre los más necesitados, la bellota tendría dos salidas: el consumo, algo que no se documenta directamente, pero que cumpliría la misma función que la castaña en las zonas de montaña ${ }^{89}$, y su venta. En todo caso, las fuentes permanecen mudas sobre el destino concreto de este recurso.

La pesca como dedicación complementaria y no profesional aparece como otra actividad realizada por los pobres. La prohibición condal de pescar en el Guadiana, el Ruecas y el Búrdalo ocasionó graves consecuencias a «muchos pobres [que] se sostenían con la dicha pesca» y que se verán obligados por «nesçesidad» a "pedir limosna para sostenerse a sí e a sus mugeres e hijos». En 1537, los procuradores de las aldeas protestan por la imposición de vedas y las dificultades establecidas para la pesca por idéntica razón ${ }^{90}$.

84 AGS-CR, leg. 231, exp. 9, fol. 7v.

85 AGS-CR, leg. 230, n. ${ }^{\circ} 2$ bis, fol. $72 \mathrm{v}$.

86 AGS-CR, leg. 87, exp. 14, fol. 38r, a. 1534; y leg. 230, exp. 2-1, fol. 52r, a. 1543.

87 AGS-CR, leg. 231, exp. 5, fol. 46v; para los testigos, fols. 60v y $72 \mathrm{r}$.

88 AGS-CR, leg. 230, exp. 2-1, fol. 52r.

89 Clemente Ramos, Julián. «Explotación del bosque y paisaje natural en la Tierra de Plasencia (1350-1550)». En IX Congreso de Historia Agraria. Bilbao, 1999, pp. 448-449.

$90 \quad$ AGS-CR, leg. 230, exp. 1, fol. 32r, y exp. 4, fol 37v. 
La política concejil y los usos vecinales propiciaron el desarrollo de una forma de explotación muy definida de la ribera del río Hortiga, dentro del ejido de la villa. Este espacio se cerró a cualquier apropiación individual y se destinó a «praderas e pastos e descansaderos» para bueyes y bestias, y para que "las personas pobres neçesitadas se remediasen sus vidas con la yerva que dello segasen y vendiesen ${ }^{91}$. Como en los anteriores casos, vemos la vinculación entre un derecho comunal, una forma de explotación y un aprovechamiento específico de este colectivo desheredado. Es muy llamativo que en este caso se nos especifica el destino, la venta de la hierba segada.

Estas tres actividades, que no serían las únicas, presentan un perfil muy preciso. Permiten el acceso a una serie de recursos que contribuyen al autoconsumo o a la obtención de ingresos adicionales. A su vez, posibilitan en algunos casos la disponibilidad de una limitadísima cabaña. Los pobres se ven obligados a hacer uso de todos aquellos recursos a los que pueden acceder para posibilitar el mantenimiento familiar. Además del acceso a estos recursos, que no serían exclusivos de los pobres, pero que para estos adquieren una especial relevancia, este colectivo se convierte en algunas ocasiones en receptor de alimentos. Las renta de las vacas ${ }^{92}$ o los animales sacrificados en las dehesas durante la montanera se destinan parcialmente a ellos. A principios del siglo XVI, se precisa en la sentencia del bachiller Alonso Hernández de Chaherrero que la cuarta parte de la carne proveniente de la renta de las vacas se destine a hospitales y pobres. Esta costumbre, cuya antigüedad desconocemos, se ha mantenido en las décadas siguientes. En las cuentas de 1541-1542, se alude entre los propios de Medellín al cuarto de las vacas sacrificadas destinado a los pobres durante el desacoto de la bellota. En 1532, Juan Zimbrón precisa con más detalle que la cuarta parte se reparte «por los espitales e presos de la cárçel y a otras personas pobres desta villa». No sabemos si se terminó de implantar la sentencia de Francisco de Amarilla, de 1540, que ordenaba el reparto entre la villa, los oficiales y los pobres ${ }^{93}$.

Además de esta costumbre, que ha dado origen a unos usos muy definidos, los toros que recibía la villa en algunas rentas eran motivo para el reparto de carne, posiblemente ocasional, entre los pobres, pese a que debía haberse destinado a otras funciones. No parece que se haya convertido en algo habitual. Entre 1538-1543, el concejo de Medellín obtuvo alrededor de una docena de toros cada ańo por rentas como la treintena, el verde, el almotacenazgo o las dehesas de propios. Estos animales se destinaban a la lidia. También se destinaban otros toros a idéntico fin mediante compra o apropiación. Esto significa que se lidiaría un número significativo de ejemplares. Según Alonso de San Pedro, la carne de estos toros se aprovechaba «por los pobres y ospitales y por las personas que hazen las talanqueras». Los testigos ratifican parcialmente esta afirmación, aunque el conde parece haber introducido cierta discrecionalidad ${ }^{94}$. El reparto de la carne de

\section{AGS-CR, leg. 230, exp. 4, fol. 59r, a. 1536.}

Sobre esta renta, cf. Clemente Ramos, «El espacio pecuario», pp. 525-528.

AGS-CR, leg. 140, exp. 2, fols. 113r y 7v; y leg. 230, exp. 4, fol. 17r.

94 AGS-CR, leg. 140, exp. 2, fols. 280r, 338v y 341r-342r. Las sentencias sobre las cuentas de los años 1538-1539 a 1542-1543 recogen la obligación de destinar los toros a la contrucción del puente (por ejemplo: Ibídem, fol. 413v). 
las vacas y los toros sacrificados ha permitido una vía de abastecimiento cárnico, sin duda irregular y sobre todo insuficiente, pero importante, entre personas en situación de pobreza extrema.

Diversos mecanismos posibilitan a personas en situación de pobreza el acceso a recursos que les permiten obtener bienes de consumo y/o desarrollar modestas actividades productivas. Estamos ante economías familiares que se definen por su estrechezy versatilidad. Las pinceladas indicadas ahondan en una realidad que requeriría un tratamiento pormenorizado y monográfico a escala regional e interregional. Sin duda, muestran una enorme sensibilidad social dentro de los concejos, que intentan desarrollar su poder dentro de un cierto consenso social.

\section{Comunalismo agrario y Sociedad rural: el EJemplo de Villar de Rena}

El caso de Villar de Rena presenta unas características específicas derivadas de la comunalización de las hojas de cultivo. No sabemos hasta qué punto esta realidad tuvo difusión en la tierra de Medellín. No se documenta en las ordenanzas de Don Benito o Mengabril. El comunalismo agrario tiene una incidencia clara en la estructura de la sociedad rural. Reduce las desigualdades sociales y particularmente la pobreza rural. Hemos abordado recientemente el estudio de Villar de Rena a mediados del siglo XvI basándonos fundamentalmente en dos preguntas de un interesante interrogatorio ${ }^{95}$. Realizaremos aquí una breve síntesis para precisar la originalidad y las particularidades de la sociedad rural de esta aldea.

Villar de Rena y, en general, las comunidades que realizan la comunalización de las hojas cerealistas presentan una sociedad más equilibrada. La acumulación patrimonial de los grupos más acomodados y la pobreza tienen un menor desarrollo. Todos los vecinos de Villar, dispongan o no de bueyes ${ }^{96}$, tienen derecho a recibir ocho-nueve fanegas, quizás más. Pobres y viudas parecen recibir lotes más reducidos. Es posible que algunos de estos últimos, ante la imposibilidad de cultivarlas o de alquilar bueyes, optaran por su acensamiento. En todo caso, este recurso se considera un elemento fundamental para su mantenimiento. Este hecho supone una circunstancia muy especial dentro de una sociedad que presenta una creciente estratificación y un acceso a la propiedad cada vez más restringido ${ }^{97}$.

La propiedad de bueyes debía estar muy extendida en Villar de Rena. En un listado de penas sobre ramoneo de bueyes en el ejido del Villar y en las dehesas de Vivares y Rinconcillo aparecen cincuenta y dos vecinos. Este dato debemos relacionarlo con una población total de alrededor de sesenta vecinos. Las penas impuestas, entre 0,5 y 6 reales,

95 Clemente Ramos, «El régimen agrario de Villar de Rena», especialmente pp. 9-19.

${ }_{96}$ En otros lugares que cuentan con hojas de cereal comunalizadas, el reparto de tierras está muy vinculado al número de bueyes poseído: Clemente Ramos, Julián. «Paisaje agrario y sociedad rural en Holguera (siglos XIII-XvI)». Hispania. Revista Española de Historia, 2009, vol. LXIX, n.o 231, p. 62; ÍDEM. Ordenanzas de Galisteo (1531). Cáceres, 2001, pp. 42-44. Bohórquez Jiménez, Domingo. Ordenanzas de Valencia de Alcántara. Cáceres, 1982, pp. 67-68.

${ }^{77}$ Clemente Ramos, «El régimen agrario de Villar de Rena», pp. 12-13. 
debemos relacionarlas con los animales poseídos. Es llamativo que el que paga la más elevada disponga de un criado o doméstico ${ }^{98}$.

Este modelo económico de Villar de Rena explica la existencia de una inmigración sostenida. Entre las anualidades de 1541-1542 y 1542-1543, se conceden por el concejo de la villa de Medellín trece vecindades en esta aldea, que suponen entre un cuarto y un quinto de la población. Esta situación se produce junto a un cierto estancamiento demográfico. No sorprende que un testigo afirme, lo que coincide con los datos disponibles, que, "por la largura de pastos e tierras que tiene, a visto este testigo que se an ydo e van a bibir al dicho lugar otras gentes de otras partes» ${ }^{99}$.

La aldea de Villar de Rena rompe el modelo dominante de la sociedad campesina caracterizado por la existencia de élites o sectores enriquecidos de reducido peso demográfico y un colectivo de asalariados, en sus diferentes versiones, y pobres muy numeroso. Frente a ello, la comunalización de las hojas de cultivo, garantía de acceso a su explotación, y la importante difusión de la propiedad boyal, elementos que debemos considerar estrictamente relacionados, posibilitan que los labradores disfruten de un importante peso demográfico y no solo económico o fiscal. La privilegiada situación social y económica de esta aldea explica que se concentre en ella una parte muy significativa de las vecindades concedidas en el bienio indicado.

\section{Conclusiones}

La sociedad rural se presenta en Medellín, con la excepción señalada de Villar de Rena, como una sociedad crecientemente diversificada y estratificada. Frente a unos grupos rurales favorecidos que se elevaban poco sobre el nivel de un simple labrador en la plena Edad Media, a lo largo del siglo xv se desarrollan colectivos que se caracterizan por una importante acumulación patrimonial y/o por la configuración de explotaciones con una creciente vinculación con el mercado. Estos colectivos, en una sociedad que desde mediados del siglo XIV se presenta crecientemente estamentalizada, limitan su ascenso al ámbito económico.

El perfil de los colectivos más favorecidos se presenta con cierta nitidez. En un contexto de enorme importancia de las dehesas y la actividad pecuaria, se documenta un colectivo pechero muy vinculado al negocio ganadero. Este grupo accede a la explotación del espacio adehesado y dispone de pastores. Su cabaña se compone mayoritariamente de vacas. Este colectivo presenta un perfil similar al de los serranos y riberiegos que traen su ganado a la jurisdicción. Solo en un caso hemos podido conocer con detalle el patrimonio. El mayoral Juan Rubio ha alcanzado un nivel económico muy elevado y su explotación, centrada de forma casi exclusiva en el negocio pecuario, debe afrontar gastos anuales muy elevados en hierbas. Su implicación en el pequeño préstamo nos muestra la incidencia que este grupo pudo llegar a tener en el mundo rural.

98 Clemente Ramos, «El régimen agrario de Villar de Rena», pp. 14-15.

99 Clemente Ramos, «El régimen agrario de Villar de Rena», pp. 10-11. 
A este sector de ganaderos medios se une otro colectivo que podemos definir como labradores acomodados. La acumulación se realiza dentro del modelo económico campesino. Este grupo dispone de un número significativo de bueyes y desarrolla una actividad pecuaria centrada en gran medida en el sector porcino. Sin duda, es el gran beneficiario de la montanera, que ha mantenido en la tierra de Medellín su carácter comunal. Estamos ante cabañas porcinas de unas decenas de ejemplares que requieren la participación en algunos casos de jóvenes criados.

El grupo de labradores mantiene su importancia. Esta realidad la hemos podido constatar a través de indicios indirectos. Constituyen un grupo consistente en aldeas como Miajadas o Guareńa, que se encuentran entre las más pobladas de la jurisdicción. Igualmente en Mengabril, con un limitado grupo de campesinos enriquecidos, poseerían la mayor parte del ganado boyal. La situación no sería distinta en Villar de Rena, pero en este caso estamos ante un modelo social muy definido y particular. Este grupo de labradores no disfruta de una situación desahogada. Algunos de ellos realizan actividades complementarias u ofertan mano de obra juvenil. Sin duda, debían mantener un equilibrio inestable que generaría casos tanto de enriquecimiento como de empobrecimiento.

La cara contraria y complementaria del proceso de enriquecimiento y acumulación patrimonial que se documenta a lo largo del siglo xv es el numeroso colectivo que, con recursos insuficientes o inexistentes, hace depender sus ingresos del trabajo asalariado o se incluye directamente dentro de la pobreza. Sin duda, este grupo presentaría muchos matices. Integraría desde pastores, que unirían a su salario un pequeño capital ganadero que les permitiría subvenir a sus necesidades, a pobres en su sentido más estricto. Este último sector dependería en gran medida de una economía informal y de ingresos o recursos de procedencia muy variada, como los derechos comunales o la beneficencia social.

La sociedad rural medellinense entre 1450 y 1550 se define por su creciente polarización. Se perfila con gran claridad un grupo enriquecido. La pobreza aparece como un fenómeno de creciente importancia que genera una clara sensibilidad en el poder local. Los labradores, que hasta entonces han constituido la auténtica columna vertebral de la sociedad rural, mantienen un peso demográfico y económico relevante aunque imposible de precisar en términos cuantitativos. 